practice should include the measurement of serum levels and the avoidance of polypharmacy; and drug firms should cease the manufacture of combined tablets of phenobarbitone and of anticonvulsants whose major action is to increase the serum levels of other more active preparations.

The debate has been narrowed to epilepsy and the private motorist. Why, one may ask, is a person with a history of epilepsy, perhaps in the distant past, provided with a special licence and thus discriminated against, whereas psychiatric illness, visual defects, or cardiovascular diseases before 70 years of age do not affect a person's fitness to hold an ordinary licence? Should the same regulations govern motor boats, light aircraft, or gliders? What obligation has a doctor to give correct and early advice to a person who has had a fit after years of age before he univittingly seeks a career driving public service or heavy goods vehicles or undertakes work dependent on long hours at the wheel?

Department of Neurology,

Royal Infirmary,

Preston, Lancs

Raffle, A, ed, Medical Aspects of Fitness to Drive, 3rd edn. London, Medical Commission on Accident Prevention, 1976.

$*_{*}^{*}$ The first sentence of our article implies that doctors are expected to assess and advise patients on the effects of any disability on driving in the light of the new regulations. Like all the laws of the land, the driving licence regulations have to be applied automatically, but when assessment of individual cases is a maiter for expert medical judgment specialist advice will be obtained. In our article the current regulations were set out in detail and the interpretation and application of the regulations were outlined in a way that (it was hoped) would satisfy those closely concerned. It was not, of course, suggested that advice to alter treatment for a recurrent fit would be casual, and we agree with Dr Critchley that measurement of serum drug levels and avoidance of combined tablets and of polypharmacy are important in the modern management of epilepsy. These current views about methods of improving seizure control are well worth emphasising, though one could hardly expect to encompass all possible aspects within the constraints of a leading article focusing on fitness to drive.

Dr Critchley is not correct in saying that psychiatric illness, visual defects, or cardiovascular diseases before 70 years of age do not affect a person's fitness to hold an ordinary licence. In fact, licence holders are required by law to inform the Licensing Centre as soon as they became aware that they are suffering from any "relevant" disability (that is, one likely to cause the driving of a vehicle to be a source of danger to the public), or a "prospective" disability which, by virtue of its intermittent or progressive nature or otherwise, may in time become a relevant disability. In such cases, where appropriate, the licence is revoked or replaced by a more limited licence.-ED, $B M Y$.

\section{Meditation or methyldopa?}

SIR,-A key statement in your leading article (12 June, p 1421) on this subject requires considerable qualification if it is not to be grossly misleading.
You state that "a well-conducted and controlled clinical trial of antihypertensive treatment in the United States in men with diastolic blood pressures between 90 and $115 \mathrm{~mm} \mathrm{Hg}$ showed that the death rate from hypertension was reduced significantly and the overall incidence of complications correspondingly diminished." It is essential to note three points about the important trial ${ }^{1}$ to which you refer: (a) definite evidence of benefit was found only in those with a diastolic pressure of $105 \mathrm{~mm} \mathrm{Hg}$ or over; (b) the diastolic pressure was recorded at the fifth phase, not at the fourth phase as is customary in Britainthe fourth phase is on average at least $5 \mathrm{~mm} \mathrm{Hg}$ higher; and $(c)$ the blood pressures on which the study was based were not the patients' "casual" pressures, which would probably have been at least $5 \mathrm{~mm} \mathrm{Hg}$ higher.

Thus it is probably true to say that there is as yet no conclusive evidence of benefit from antihypertensive treatment in the case of middle-aged men with "casual" fourth-phase diastolic pressures below $115 \mathrm{~mm} \mathrm{Hg}$."

\section{DAVID SHORT}

Cardiac Department,

Aberdeen Royal Infirmary, Aberdeen

Veterans Administration Cooperative Study Group,

Fournal of the American Medical Association,
213, 1143.
Short, D, British Heart fournal, 1975, 37, 893.

\section{Nodular vasculitis of tuberculous} origin in an elderly woman

SIR,-Classical descriptions of the Bazin form of erythema induratum emphasise its preponderance in young women. However, at least five cases of Bazin's disease have been reported in women aged $51-57 . .^{2}$

Nodular vasculitis, on the contrary, affects chiefly women aged $30-60 . .^{3}$ The syndrome is a hypersensitivity reaction to many causes, of which tuberculosis is one, and in a number of cases the exact cause of this clinical entity remains obscure. In some such cases the response to prolonged antituberculosis therapy provides the solution." Since we have diagnosed nodular vasculitis of tuberculous origin in a woman aged 84 we wish to draw attention to the fact that at any age tuberculosis has still to be considered as a cause of chronic nodular lesions of the legs.

An 84-year-old woman had been well until two months previously, when she noticed the eruption of tender nodules on both her legs. There were no other symptoms. On examination multiple tender, subcutaneous, red and purplish nodules without ulceration were present on the anterior aspects of the legs below the knees, the inner aspect of the right ankle, and the dorsa of the feet. The nodules ranged in size from 1 to $2 \mathrm{~cm}$, some of them forming plaques. No other abnormalities were found.

The urine was normal. The haematocrit value was $40^{\circ} \ldots$. The white cell count was $8.2 \times 10^{9} 1$ $\left(8200 \mathrm{~mm}^{3}\right)$ with a normal differential count and the platelet count was $143 \cdot 10^{9} / 1\left(143000 / \mathrm{mm}^{3}\right)$. The ESR was $55 \mathrm{~mm}$ in 1 hour (Westergren). C-reactive protein was present $(\ldots \ldots)$. The antistreptolysin titre was 125 Todd units. Rheumatoid factor, antinuclear antibodies, and LE cells were not found. The total plasma protein was $87 \mathrm{~g} /$ with albumin $48 \mathrm{~g} / \mathrm{l}$ and globulin $39 \mathrm{~g} / \mathrm{l}$, with and increase in the gamma component $\left(34^{\circ}{ }^{\circ}\right)$. A skin tuberculin test (OT 1:10000) was positive $(\ldots \ldots)$. No mycobacteria or other pathogens were found in the sputum or urine. A throat culture was negative for $\{$-haemolytic streptococci. $X$-ray and tomography of the chest showed no abnormalities. Biopsy of a skin nodule revealed typical tubercle formation with caseation. Treatment with streptomycin, isoniazid, and ethambutol was initiated. During the next 20 days some of the lesions became smaller and a few healed, leaving atrophy. The patient was then discharged to continue the same treatment. Two months later no skin lesions were present and after eight months the patient was well and the plasma $\gamma$-globulin level and the ESR were normal.

Nodular vasculitis among the middle-aged or elderly is not often attributed to tuberculosis. The tuberculous origin of nodular vasculitis is too seldom considered a possibility in the differential diagnosis of leg nodules in the elderly. Personal and family history and radiological, histological, and bacteriological investigations may at times fail to disclose any evidence of tuberculosis." In unexplained cases of nodular vasculitis a strongly positive tuberculin reaction ${ }^{4}$ combined with an increase of $y_{\text {-globulin concentration }}{ }^{3}$ should suggest the possibility of tuberculosis and the response to adequate and prolonged antituberculosis therapy" is " may confirm this diagnosis."

St K BARTSOKAS

J Stratigos

A ARCHIMANDRITIS

G Rigatos

$S$ BEGIETI

Department of Pathological Physiology,

Section of Internal Medicine,

National University of Athens, Greece

'Montgomery, H, O'Leary, P A, and Barker, N W, Collected Papers of the Mayo Clinic, 1944, 36, 461 . Feiwel, M, and Munro, D D, British Medical fournal, 1965, 2, 1109.

Rook, A, Wilkinson, D S, and Ebling, F J G, Textbook of Dermatology. vol 1, p 675. Oxford and Edinburgh, Blackwell Scientific, 1969.

Stegmaier, O, Archives of Dermatology, 1959, 80, 350. British Mcdical Fournal, 1963, 2, $98 \mathrm{i}$

'Benians, R G, British Medical fournal, 1963, 2, 1267.

\section{Natural history of chronic bronchitis}

SIR,-In your leading article on this subject (29 May, p 1297) you start with the hypothesis that mucopurulent bronchitis is a stage on the road to obstructive bronchitis, with a reference ${ }^{1}$ in which I can find no evidence for this claim. You follow by stating that infection is one of the factors leading to the "development and progression" of bronchitis, with a reference to the late Professor J R May's book on the chemotherapy of chronic bronchitis ${ }^{2}$ in which I can find no evidence to support this statement. Indeed, the preface only claims that "it may be that long continued effective suppression of the relevant pathogenic bacteria will ultimately be shown to delay the progressive deterioration of pulmonary function to which most bronchitics are subject." Finally you state, without any references, that the bronchitic's "respiratory function invariably worsens" with mucopurulent episodes.

In a leading article in 1973:" you made the same claim about the effects of respiratory infections on lung function in bronchitis and

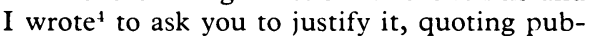
lications which showed that they very rarely have any permanent effect. A further paper confirming this evidence has recently been published." And surely the finding by Johnston and his colleagues, ${ }^{6}$ which you quote, that antibiotic treatment had no effect on the decline in forced expiratory volume makes it improbable that infection itself has much effect on it. 
Have you now got any actual evidence to support your hypothesis about infections causing irreversible airflow obstruction ? If not, why do you go on advancing it as if it were proved?

\section{M FletCher}

Royal Postgraduate Medical School,

London W12

Medical Research Council, Lancet, 1965, 1, 775

May, J R, The Chemotherapy of Chronic Bronchitis and Allied Disorders, 2nd edn, London, Englis Universities Press, 1972

${ }^{3}$ British Medical fournal, 1973, 4, 437.

Fletcher, C M, British Medical fournal, 1973, 4, 672

Fletcher, C M, Community Health, 1975-6, 7, 70.

***In our article we were at pains to point out that "many of the factors leading to progression of the disease are still an enigma," and the roles of cigarette smoking, atmospheric pollution, dusty occupations, and infection were discussed. The association of infection with airways obstruction is clearly stated in a report to the Medical Research Council by the committee on the aetiology of chronic bronchitis, ${ }^{1}$ of which Professor Fletcher was secretary. In this report the following appears "Two other manifestations frequently occur: bacterial infection, which may result in mucopurulent sputum and generalised airways obstruction. Thus it is possible to recognise simple, mucopurulent, and obstructive forms of chronic bronchitis separately or in combination with each other." That infection may cause permanent changes is contained in the following extract from the same paper: "Exacerbations of infection with the production of purulent sputum are a common feature of chronic bronchitis. Since these episodes may be disabling in themselves and may ultimately lead to permanent bronchial and pulmonary damage, those cases in which the sputum is persistently or intermittently mucopurulent, indicating active bronchial infection, may usefully be distinguished from those in which it is mucoid." There is some pathological evidence that episodes of infection lead to progression of the disease, ${ }^{2}$ but, as we pointed out, treatment of bronchial infection does not appear to halt the deterioration in pulmonary function.-ED, $B M \mathcal{F}$.

1. Medical Research Council, Lancet, 1965, 1, 775.

Reid, L, in Recent Trends in Chronic Bronchitis, ed N C Oswald. London, Lloyd-Luke, 1958.

\section{New look at malaria}

SIR,-Dr S L Henderson Smith (5 June, $\mathrm{p}$ 1402) asks whether it is humane to eradicate malaria in African countries as this will lead to a further increase in population with subsequent starvation. He suggests that the WHO should concentrate instead on family planning in these areas.

Having worked in one country in Africa for some years, may I make the following points? There are already several organisations and many individuals who are working in the field of family planning in Africa. Before their efforts can be effective their programmes must first gain acceptance by the governments concerned, which are sometimes suspicious about the imposition of foreign ideals on their people. The decision to limit family size is a personal one which can be made only when the individuals concerned are satisfied that it is a desirable end. To most rural Africans children are regarded as an asset, and sterility is a tragedy.

Along with many others I believe that only when parents have some guarantee that their children will grow up healthy will they accept family planning. The mortality of children under 5 years in the part of Africa where worked is around $30^{\circ} \mathrm{o}$, and malaria is one of the major causes of death in that age group as well as causing much morbidity and mortality in the rest of the population. It would therefore seem to me both logical and humane for the WHO to continue to use its expertise in attempting to control this disease.

HeLEN KingstoN

Craig Dunain Hospital, Inverness

\section{Coeliac disease and diffuse lung disease}

SIR,-I am grateful to Drs O E Eade and W T Berrill (1 May, p 1076) for their comments on my report on coeliac disease and farmers' lung (27 March, p 745).

I have had an opportunity of repeating the jejunal biopsy in case 1 and this shows marked improvement. The original biopsy showed subtotal villous atrophy with a mosaic pattern and the repeat biopsy after one year on a glutenfree diet shows regeneration of villi with persistence of chronic inflammatory cells. The patient's weight has increased from 53 to $70 \mathrm{~kg}$ and all tests of absorption are normal

I have noted the association of farmers' lung and HLA-B8 and at present I am undertaking a larger survey on patients with farmers' lung, in whom, among other tests, histocompatibility typing is being done. I hope to publish my results.

Craigavon Area Hospital,

Craigavon,
Co Armagh

T J ROBINSON

the other three colleagues would increase to $33^{\circ}$, and in times of holidays or sickness to $50^{\circ}$ or for each of the remaining two colleagues. This would quite obviously be grossly unfair and would undoubtedly have immediate and justified repercussions among his colleagues.

Similarly, a medical Jehovah's Witness would probably refuse to give as well as to receive blood transfusions, and his convictions would surely be respected. But he should not seek to work as a physician or as a surgeon in the NHS, in which branches of medicine such practice is obligatory.

A man of high morals and convictions commands our respect. However, if he is unwilling to make any sacrifices for his principles but, on the contrary, requires that others make sacrifices for him, then some of us will question whether such admiration is justified.

R SALM

Falmouth,

\section{Restriction of right to prescribe}

SIR,-I most heartily agree with Drs B Caplan and J H Scotson (12 June, p 1471) regarding the Medical Practitioners (Restriction of Right to Prescribe) Bill. On no account should we allow non-professional people access to records for medical audit.

Most general practitioners would agree that the public's insatiable demand for drugs should be curtailed, but nothing will be achieved by the interference of vote-touting politicians with schemes which nullify the confidentiality of medical practice and cast a slur on the abilities of prescribers. The threat to freedom is sufficiently serious to warrant immediate and effective protest by the BMA.

N L HIGgINS

Neston,

Wirral, Cheshire

\section{A question of conscience}

SIR,-Mr R Walley's article (12 June, p 1456) makes sad reading, for he is both illogical and, if I may say so, a little selfish. I admire and indeed I share his respect for human life, but in my opinion his only genuine grievance is that the rules were changed while he was in training, his conscience preventing him from adapting to the new service requirements.

However, he is illogical in complaining that he is being discriminated against. The will of the people, as expressed through Parliament, now lays down that certain abortion facilities shall be provided in the NHS, and the area health authorities have the duty to see that this regulation is implemented. In all fairness, it is wrong of Mr Walley to object if the authorities prefer to engage staff who are willing to comply with the current service requirements. As a citizen it is open to $\mathrm{Mr}$ Walley to try to bring about a reversal of these new rules, but he is selfish in demanding that he be excused some of the duties which his colleagues must accept. There are many other openings in medicine and it may be recalled that some colleagues have been forced and will be forced to change their specialty because of unexpected disability or other circumstances.

If one assumes that the average clinical area is staffed by four consultant gynaecologists, then each of them will cover $25^{\%}$ of the abortion work because it is part of their job. If one of them were to contract out, the share of

\section{Priorities in the NHS}

SIR,-Dr R B Hopkinson (12 June, p 1449) commented during your conference on priorities (12 June, p 1447) on "the huge regional variation in health indices." $\mathrm{He}$ referred to the latest triennial report on maternal mortality and quoted an Oxford figure of $5 \cdot 9 / 1000$ live births and another region with a figure of $17 \cdot 2 / 1000$. This was an error. The correct figures are much better, at 5.9 and $17 \cdot 2 / 100000$ births respectively. A critical study to find reasons rather than theories for these, and other, inequalities would indeed be appropriate at this time of financial difficulty.

The Oxford results were not achieved by expensive electronic equipment, valuable though this can be when used with clinical judgment. The relevant triennium ended as the superbly equipped new John Radcliffe Hospital was opened, so it played no part in producing these results. They are the fruits of years of hard clinical work and dedicated caring by a large group of general practitioners and consultant obstetricians working in harmony in integrated teams.

Further evidence of what this can achieve is provided by the fall in perinatal mortality in general practitioner units from $30 / 1000$ in $1951-3$ to $3 / 1000$ in 1970 , with an associated progressive fall in the uncorrected figure for the combined consultant-practitioner division 